\title{
Corrigendum to "Old and New NICE Guidelines for the Evaluation of New Onset Stable Chest Pain: A Real World Perspective"
}

\author{
Nazario Carrabba $\left({ }^{D},{ }^{1}\right.$ Angela Migliorini, ${ }^{1}$ Silvia Pradella, ${ }^{2}$ Manlio Acquafresca, ${ }^{2}$ \\ Marco Guglielmo, ${ }^{3}$ Andrea Baggiano, ${ }^{3}$ Giuseppe Muscogiuri, ${ }^{3}$ and Renato Valenti ${ }^{1}$ \\ ${ }^{1}$ Cardiovascular and Thoracic Department of Careggi Hospital, Florence, Italy \\ ${ }^{2}$ Radiologic Department of Careggi Hospital, Florence, Italy \\ ${ }^{3}$ Centro Cardiologico Monzino, IRCCS, Milan, Italy \\ Correspondence should be addressed to Nazario Carrabba; carrabban@aou-careggi.toscana.it
}

Received 16 December 2018; Accepted 18 December 2018; Published 7 March 2019

Copyright (C) 2019 Nazario Carrabba et al. This is an open access article distributed under the Creative Commons Attribution License, which permits unrestricted use, distribution, and reproduction in any medium, provided the original work is properly cited.

In the article titled "Old and New NICE Guidelines for the Evaluation of New Onset Stable Chest Pain: A Real World Perspective" [1], the last name of the seventh author was given incorrectly as Moscogiuri. The author's name should have been written as Muscogiuri. The revised authors' list is shown above.

\section{References}

[1] N. Carrabba, A. Migliorini, S. Pradella et al., "Old and new NICE guidelines for the evaluation of new onset stable chest pain: a real world perspective," BioMed Research International, vol. 2018, Article ID 3762305, 7 pages, 2018. 


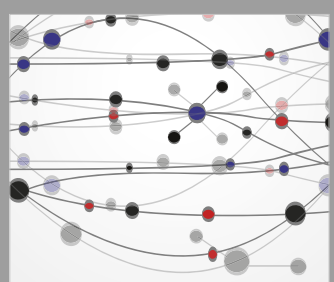

The Scientific World Journal
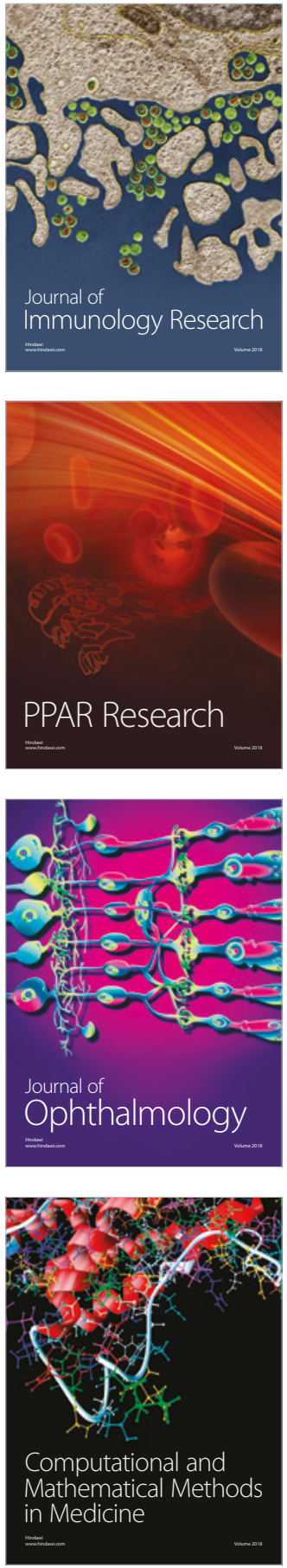

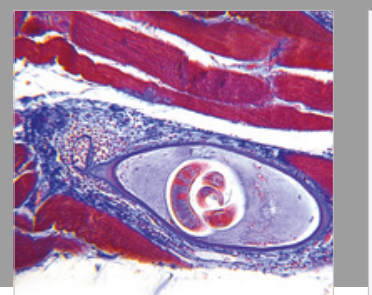

Gastroenterology Research and Practice

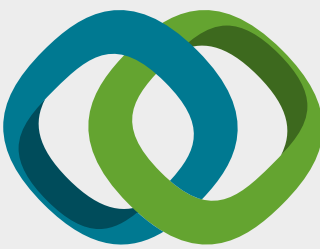

\section{Hindawi}

Submit your manuscripts at

www.hindawi.com
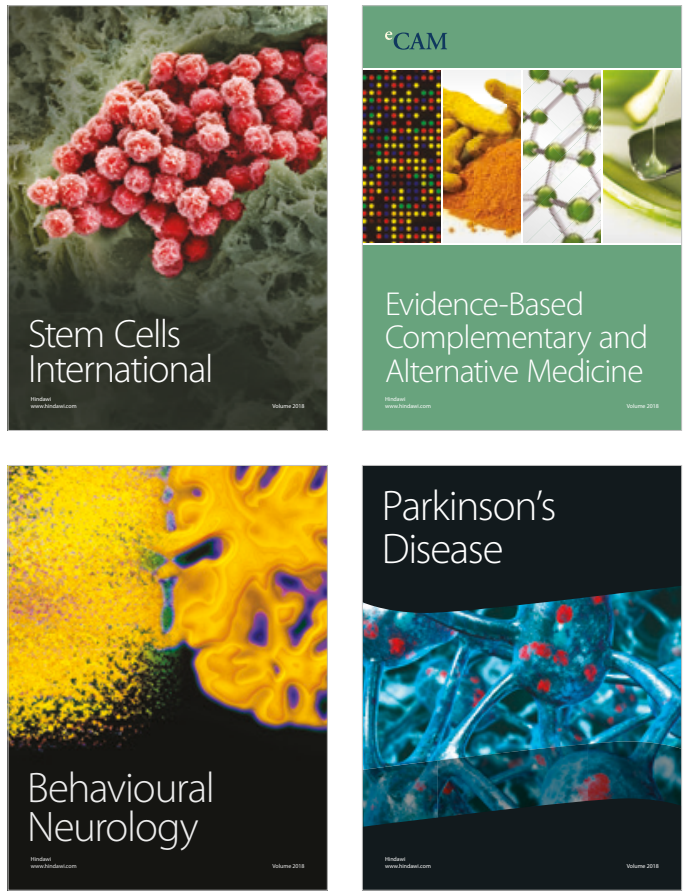

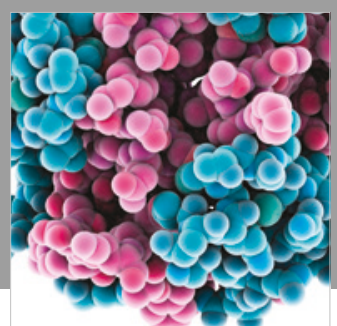

ournal of

Diabetes Research

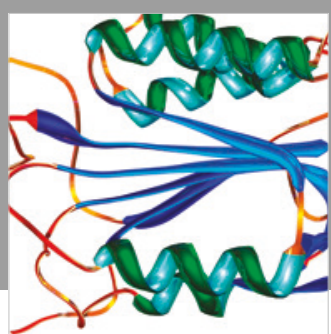

Disease Markers
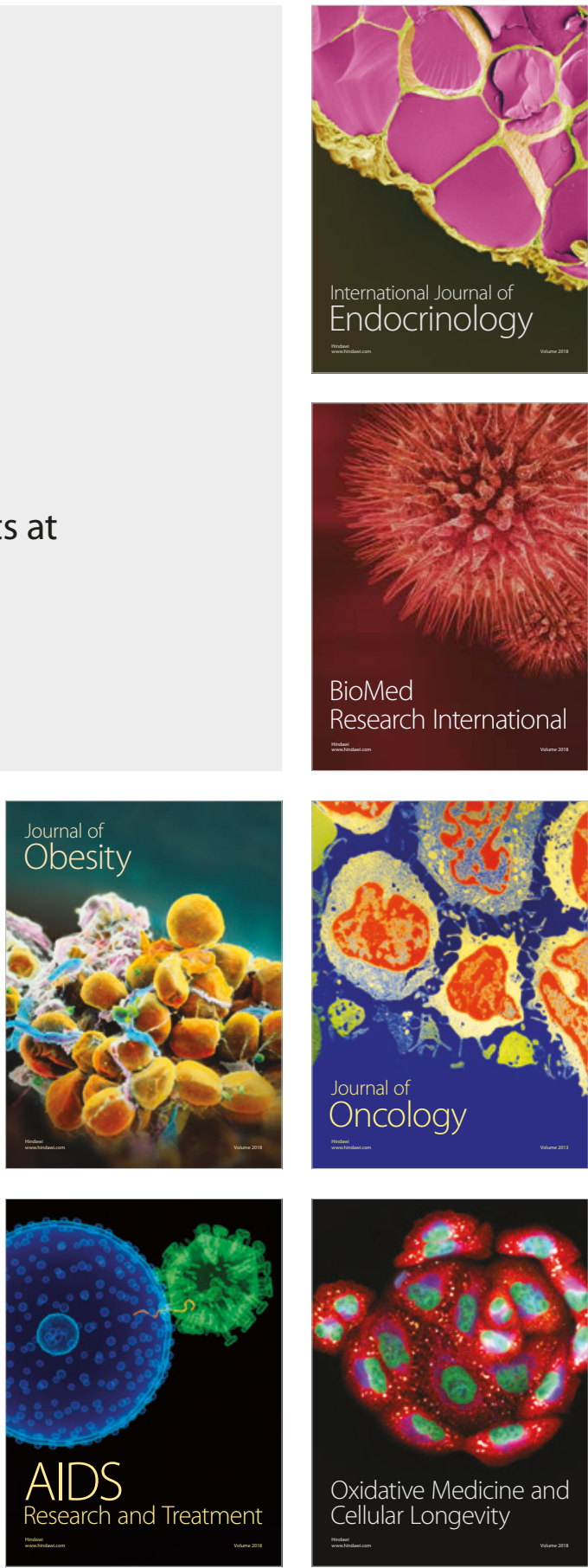